\title{
28 Research Square \\ Preferences of psychotherapists for blended mental health interventions in Germany: a discrete choice experiment
}

Elena Phillips ( $\nabla$ elena.phillips@uni-hamburg.de)

Universität Hamburg

Sebastian Himmler

Erasmus University Rotterdam

Jonas Schreyögg

Universität Hamburg

\section{Research Article}

Keywords: e-mental health, blended care, e-therapy, interventions, discrete choice experiment, therapist preferences, therapeutic alliance

Posted Date: June 24th, 2021

DOI: https://doi.org/10.21203/rs.3.rs-598895/v1

License: (c) (i) This work is licensed under a Creative Commons Attribution 4.0 International License. Read Full License 


\section{Abstract}

Objectives: Digital treatment formats are emerging within mental health care. Evidence suggests that mental health care providers and recipients prefer a combination of digital and traditional elements within psychotherapy treatment formats, also called blended care (BC), over standalone digital formats. We examined the attitudes and preferences of licensed psychotherapists in Germany regarding such BC applications.

Methods: We fielded a survey among psychotherapists, including questions about attitudes, previous experiences, and expectations regarding $\mathrm{BC}$, as well as a discrete choice experiment. Attributes for the experiment were developed using a stepwise qualitative approach. A Bayesian D-efficient design was used to generate the choice tasks. The choice data were analyzed by applying mixed logit models.

Results: The survey was completed by 200 psychotherapists. Attitudes towards BC were mainly positive, with strong reported intentions to use $\mathrm{BC}$ formats. In the choice experiment, recommendation from a professional society for a BC online component was the most important characteristic. Greater effectiveness and a larger share of face-to-face vs. online time were also desired features, while a financial incentive to use BC was less relevant.

\section{Introduction}

In light of the ongoing COVID-19 pandemic, calls for the use of digital technology in mental health have increased [1]. Lockdowns have forced many therapists and patients to turn to videoconferencing as a substitution for face-to-face sessions and rekindled interest in e-mental health interventions, also called online- or web-based therapeutic interventions (eMHIs) [1]. eMHls are self-help-based, usually short-term therapeutic programs mainly based on cognitive behavior therapy (CBT) for patients with mild and moderate symptoms [2]. eMHls usually include some remote interaction with a psychologically skilled coach or therapist via e-mail, telephone or video conferencing [3]. eMHls have been found to be effective in improving mental health and treating psychological conditions, such as psychological distress, burnout, depression, anxiety, insomnia, eating disorders, or problematic substance use [3-5].

Despite advantages for patients in terms of the flexible delivery of eMHIs, their adherence and acceptability among the general population remain limited compared to face-to-face psychotherapy. Studies on the acceptance barriers associated with eMHIs revealed a strong patient preference for personal contact in the therapy process [6-7]. Emerging blended care $(\mathrm{BC})$ treatment formats combine the use of eMHIs and traditional face-to-face therapy, aiming to link the advantages of technology and personal contact with a therapist [8]. According to current evidence, patients experience blended formats positively and seem to prefer $\mathrm{BC}$ to the standalone use of eMHIs [9-12]. A strong preference for blended types of interventions was also confirmed in a recent study from Germany using a discrete choice experiment (DCE) [10]. Results along the same lines were found in a survey on attitudes towards digital treatment of depression in eight European countries [11]. 
The first studies on attitudes towards eMHIs among mental health care providers, predominantly psychotherapists and psychologists, have shown similar tendencies; therapists prefer BC over the standalone use of eMHIs and associate BC with lower risks and disadvantages [12-15]. Attitudes towards BC vary depending on geographical location or therapeutic orientation. Therapists in countries with a higher level of dissemination of e-mental health, such as the Netherlands, Sweden and United Kingdom, express optimistic attitudes towards BC; by contrast, therapists in countries such as Austria and Germany, with lower e-mental health utilization, or France, with a strong tradition of psychodynamic therapies, emphasize disadvantages and risks regarding eMHIs and hesitation regarding future use [11, 15-16]. CBT-trained professionals are more optimistic about eMHIs and blended interventions in general than therapists with other therapeutic backgrounds $[11,13-15,17]$.

In general, it is still unclear why psychotherapists are hesitant to use BC and under which conditions they would be ready to use eMHIs. One complicating factor in exploring attitudes towards $\mathrm{BC}$ is the lack of coherent understanding or definition of $B C$, which can be implemented in various forms $[8,18]$. The $B C$ format depends on the type of online components used, the extent to which online and personal sessions are combined, and the chronological order in which the online component will be applied-before, parallel to or after personal therapy $[8,12,18]$. Preferences for $B C$ use may depend on the configuration of the $B C$ format and application scenarios; however, no study has investigated the preferences of psychotherapists considering different BC application scenarios thus far.

The aim of our study was two-fold. First, we wanted to explore previous experiences with and expectations for using $\mathrm{BC}$ and attitudes towards specific features of $\mathrm{BC}$ among psychotherapists in Germany, a country with low e-mental health utilization with an increasing need for timely and adequate psychotherapy [17]. Second, given the low diffusion of $\mathrm{BC}$ and hesitation regarding eMHIs among German therapists $[15,17]$, we were interested in understanding psychotherapists' preferences regarding BC formats and application modes. Therefore, we conducted a DCE, which entails choices between hypothetical blended treatment options, thus making blended treatment more tangible to participants than is possible with conventional survey techniques. To our knowledge, this is the first DCE that explored preferences among psychotherapists regarding eMHIs or BC. Knowing which BC application scenarios are preferred by therapists can help policy makers and $\mathrm{BC}$ program developers to facilitate conditions and design $\mathrm{BC}$ formats that are more attractive to therapists, which could increase the acceptance and uptake of such techniques among different providers in in- and outpatient settings. With citizens and patients in Germany and elsewhere seemingly open to the use of BC [10], this could shift some parts of certain forms of mental health care to a digital format, thus freeing up therapeutic resources for other purposes.

\section{Methods}

We designed a survey with two distinct parts: The first part consisted of a series of questions on therapists' experiences with and expectations for BC, as well as their attitudes towards specific BC features. To develop these questions, we consulted the related literature, especially Dijksman et al., who 
conducted research to identify further BC online components and inquired about their relevance in exploratory interviews with five psychotherapists. The second part of our survey and study consisted of a DCE, which included four steps: (1) defining attributes and levels for the experiment; (2) generating the experimental design and survey; (3) piloting the survey; and (4) collecting the data. The DCE design development followed best practice guidance, including consideration of the 10-point checklist for conjoint experimental design provided by the International Society for Pharmacoeconomics and Outcomes Research (ISPOR) [19].

\section{Development of attributes and levels}

Attributes and levels for the DCE were developed using a stepwise qualitative approach. First, we conducted a literature review on $\mathrm{BC}$ with a focus on therapists' perceptions of and barriers to the use of $B C[12-13,15-16]$. In the second step, we structured the identified factors that promote or hinder the use of blended treatment using the unified theory of acceptance and use of technology (UTAUT), formulated by Venkatesh [20]. Venkatesh et al. defined four core determinants of users' behavioral intention to use a technology: performance expectancy, effort expectancy, social influence, and facilitating conditions [20]. According to previous research, performance expectancy has the largest impact on the intention to use the technology [21]. Tailoring this to the context of $\mathrm{BC}$, we included the attribute effectiveness of the online component used in blended treatment in our DCE design. Effort expectancy refers to the perceived difficulty of using the technology. As effort expectancy highly depends on the type and form of online components being used, it was not included as an attribute. Social influence describes the degree to which individuals perceive that individuals or organizations whose opinions and views they appreciate believe that they should use a certain technology. Anticipating peer effects, we included social influence as the recommendation attribute, relating to both recommendations by colleagues and recommendations by professional society. Last, facilitating conditions are defined as organizational or technical conditions that encourage technology use [20]. We translated this determinant as a reimbursement attribute, which includes a financial incentive for therapists that could encourage the adoption of $\mathrm{BC}$ [22]. Because an important adoption factor identified in previous research was the presence of a good therapeutic relationship, which depends on the concrete operationalization of the blended treatment-the number of face-to-face sessions and amount of independent work of the client with the online component-we included the attribute ratio of online and personal sessions in our design [12,14-16]. The levels corresponding to the attributes were chosen not only to reflect realistic scenarios but also to provide a spread enabling respondents to differentiate between levels. We conducted semistructured interviews with five therapists with different specializations (two CBT, one psychodynamic, two humanistically oriented psychotherapists) and refined our selection of attributes and levels. The final experimental design included five attributes with two to three levels each (see Table 1). 
Table 1

Description of attributes and levels

\begin{tabular}{|c|c|c|}
\hline Attribute & Level & Description \\
\hline $\begin{array}{l}\text { 1) } \\
\text { Recommendation }\end{array}$ & $\begin{array}{l}\text { From a } \\
\text { colleague; } \\
\text { from a } \\
\text { professional } \\
\text { association; } \\
\text { none }\end{array}$ & $\begin{array}{l}\text { This feature refers to a recommendation that you received for } \\
\text { the online component (tool or therapy program). }\end{array}$ \\
\hline $\begin{array}{l}\text { 2) Proven } \\
\text { effectiveness }\end{array}$ & $\begin{array}{l}9 \text { out of } 10 \\
\text { clients; } 8 \\
\text { out of } 10 \\
\text { clients; } 7 \\
\text { out of } 10 \\
\text { clients }\end{array}$ & $\begin{array}{l}\text { This attribute describes the clinical effectiveness of the online } \\
\text { component in comparison to no therapy based on the first } \\
\text { studies, e.g., in the form "For } 9 \text { out of } 10 \text { clients, the online } \\
\text { component (tool or program) was clinically effective". Since } \\
100 \% \text { effectiveness has not yet been proven, the following } \\
\text { options can be chosen: } 7 \text { out of } 10,8 \text { out of } 10 \text {, and } 9 \text { out of } 10 \\
\text { clients. }\end{array}$ \\
\hline \multirow[t]{2}{*}{$\begin{array}{l}\text { 3) Time ratio of } \\
\text { face-to-face and } \\
\text { online sessions }\end{array}$} & 20:80; & $\begin{array}{l}\text { This attribute relates to the time invested and describes the } \\
\text { percentage (\%) ratio in which personal sessions and an online } \\
\text { component (tool or program) are combined in an individual } \\
\text { therapy process for each client. }\end{array}$ \\
\hline & & $\begin{array}{l}\text { Examples are } 20: 80,50: 50 \text { or } 80: 20 \text {, where the first number } \\
\text { reflects face-to-face sessions and the second reflects the client's } \\
\text { independent work with an online component. }\end{array}$ \\
\hline \multirow{2}{*}{$\begin{array}{l}\text { 4) } \\
\text { Reimbursement } \\
\text { for the use of an } \\
\text { online } \\
\text { component }\end{array}$} & \multirow{2}{*}{$\begin{array}{l}\text { Proportional } \\
\text { to time } \\
\text { investment; } \\
\text { proportional } \\
\text { to time } \\
\text { investment } \\
\text { + lump sum }\end{array}$} & $\begin{array}{l}\text { This attribute describes the reimbursement model for the use of } \\
\text { BC: }\end{array}$ \\
\hline & & $\begin{array}{l}\text { Proportional to the time invested for the online component per } \\
\text { therapy block (preparation, follow-up work, supervision of } \\
\text { homework, etc.) or rather proportional to the time invested for } \\
\text { the application of an online component plus a lump sum. }\end{array}$ \\
\hline
\end{tabular}

\section{Choice tasks and experimental design}

We constructed the choice tasks using unlabeled, paired comparisons. We used a fractional factorial design to reduce the response burden for participants [23]. A D-efficient Bayesian design was generated using JMP software from the SAS Institute. The design was optimized for main effects and all one-way interactions based on a conditional logit model. Attributes and levels were dummy coded, and Bayesian priors were obtained from a pretest. As the number of parameters to be estimated (main effects plus interaction effects) was larger than the maximum number of choice tasks we expected to still be feasible for respondents, the final design included 32 choice tasks that were divided into two blocks to guarantee response efficiency while facilitating robust statistical analysis. Participants were randomly allocated to one of the blocks of 16 choice tasks. An opt-out option was excluded in order to increase the amount of information collected and avoid interpretation bias [24]. 


\section{Survey design}

The survey itself started by informing respondents about the definition of $B C$ and the aim of the study. In addition to collecting sociodemographic information, the first part of the survey consisted of questions on attitudes towards and previous experience with eMHIs, as well as preferences for individual components of eMHIs, such as videoconferencing or CBT-based exercises. The second part started by familiarizing respondents with the DCE elicitation format and the types of questions that would be asked, followed by an unrelated warm-up choice task. Next, all attributes and levels of the DCE were explained in a narrative fashion before respondents had to answer the 16 choice tasks. Following the DCE, participants were asked about their general views of the advantages and disadvantages regarding BC and asked to evaluate the difficulty of DCE and the survey in general.

\section{Study pilot}

A pretest of the DCE was conducted among 30 therapists from the same respondent pool as in the main data collection. Data from the pretest were used to refine the questionnaire part of the survey, i.e., reducing the response burden [25] and to obtain the priors of the Bayesian D-efficient design.

\section{Data collection}

We administered the survey online through a market research agency specializing in health care providers (DocCheck Community $\mathrm{GmBH}$ ) to individuals who, at that time, were working as psychotherapists in Germany. Data collection occurred in August 2020. A sample of 200 respondents was targeted to provide sufficient statistical power for the DCE based on a rule-of-thumb calculation proposed by Johnson and Orme [26]. We collected explicit and informed consent from respondents after providing them with a detailed explanation of how their personal data would be used. The participants received small monetary compensation from the market research agency.

\section{Statistical analysis}

Discrete choice data are commonly analyzed based on the random-utility framework [27] by applying different statistical models, which must be selected to fit the purpose of the study [28-29]. In our case, attempting to elicit preferences for $\mathrm{BC}$ interventions among psychotherapists, who constitute a heterogeneous group concerning treatment styles or therapeutic focus, we expected a large variety of preferences. Therefore, to specifically model preference heterogeneity while also relaxing the independence of irrelevant alternative assumptions, a mixed logit model was estimated [30]. To select the utility function, the following steps were taken: First, we tested whether the inclusion of an alternative specific constant (ASC) and the inclusion of block dummy variables, indicating the survey version, would be necessary to obtain unbiased estimates based on a main effects mixed logit model [28]. Second, different functional forms of the effectiveness and face-to-face online ratio attributes were specified, namely, linear and logarithmic instead of categorical. Third, we tested several two-way interactions hetween attrihutes clicnented to he rorrelated Catennrical variables were dummy coded throughout the Loading [MathJax]/jax/output/CommonHTML/fonts/TeX/fontdata.js 
analysis. In the final mixed logit model, 500 Halton draws were specified, all parameters for which we found heterogeneity were set to be random and normally distributed, and individual-level clustered standard errors were used. Marginal effects were calculated using the mixlpred command.

To investigate whether preferences specifically differed for various subgroups, interaction terms of the respective subgroup indicators (e.g., therapeutic style, clinic or outpatient, potential user of BC, previous user of $\mathrm{BC}$, age, gender) and the main effects parameters were included in separate models. The significance of the difference in parameter estimates between subgroups was tested using $\chi^{2}$ tests for joint significance. We conducted two proposed tests to assess the internal validity of the choice experiment data [31]. First, using the respdiff command, we investigated the extent to which straight lining occurred, i.e., respondents always choosing either option A or option B, indicating a lack of serious engagement with the experiment. Second, attribute dominance, relating to noncompensatory preferences, was examined by calculating lexicography scores and counting the proportion of choices based on one attribute. We assumed attribute dominance if the lexicographic score was above $90 \%$, as suggested previously [32]. All calculations were conducted using Stata 16 (StataCorp, College Station, TX).

\section{Results}

\section{Respondent characteristics}

The survey reached 1335 psychotherapists via e-mail who were members of the DocCheck Panel. A total of 238 respondents started the survey, 38 did not complete the questionnaire, and only three dropouts occurred after starting the DCE part of the survey. Table 2 shows the respondent characteristics as well as their experiences and expectations regarding BC formats. The age and gender distribution in the sample was similar to what has been reported for the overall population of psychotherapists in Germany (49\%), while our sample likely was slightly younger [33]. We observed a realistic spread of therapeutic orientations across the main therapeutic approaches, although systemic and humanistic approaches were likely underrepresented [34]. Almost all respondents were medical psychotherapists practicing in inpatient facilities, while one-third worked predominantly in outpatient care. 
Table 2

Sample characteristics and experiences with and expectations for BC

\begin{tabular}{|c|c|c|c|}
\hline Respondent characteristics $(n=200)$ & & Experiences and expectations regarding & \\
\hline Mean age in years & 48 & Experience with BC format in therapy & \\
\hline Female & $43 \%$ & Yes & $26.5 \%$ \\
\hline Therapeutic orientation & & No & $73.5 \%$ \\
\hline Behavioral & $52.5 \%$ & $\begin{array}{l}\text { Evaluation of previous experience with } \\
\text { BC }\end{array}$ & \\
\hline Psychodynamic or analytic & $39 \%$ & Excellent & $7.5 \%$ \\
\hline $\begin{array}{l}\text { Behavioral and psychodynamic or } \\
\text { analytic }\end{array}$ & $3 \%$ & Satisfied & $54.7 \%$ \\
\hline Systemic & $1 \%$ & Neither good nor bad & $32.1 \%$ \\
\hline Humanistic & $0.5 \%$ & Bad & $5.7 \%$ \\
\hline Another & $4 \%$ & Very bad & $0 \%$ \\
\hline Professional background & & Willing to use $B C$ in the future & \\
\hline Psychological psychotherapist & $1.5 \%$ & Yes & $90.5 \%$ \\
\hline Medical psychotherapist & $89 \%$ & No & $8.5 \%$ \\
\hline Child and adolescent psychotherapist & $1 \%$ & Preferred timing of BC application & \\
\hline $\begin{array}{l}\text { Alternative practitioner for } \\
\text { psychotherapy }\end{array}$ & $0 \%$ & $\begin{array}{l}\text { Stepped care before in-person } \\
\text { treatment }\end{array}$ & $9 \%$ \\
\hline Psychiatrist & $3.5 \%$ & Integrated parallel BC & $68.5 \%$ \\
\hline Psychiatrist and psychotherapist & $3.5 \%$ & After in-person treatment & $22.5 \%$ \\
\hline General practitioner & $1 \%$ & Perceived main advantage of $\mathrm{BC}$ & \\
\hline Neurologist & $0.5 \%$ & $\begin{array}{l}\text { Time savings for therapists and } \\
\text { patients }\end{array}$ & $22.2 \%$ \\
\hline Main place of work & & Patient empowerment & $21.3 \%$ \\
\hline Own outpatient practice & $33 \%$ & Increase in treatment efficacy & $15 \%$ \\
\hline Clinic/hospital & $55 \%$ & Flexibility for therapists and patients & $7.5 \%$ \\
\hline Other & $12 \%$ & Larger patient group can be reached & $6.7 \%$ \\
\hline Satisfaction with monthly income & & Bridging waiting times for therapy & $4.6 \%$ \\
\hline Highly satisfied & $8 \%$ & Perceived main risk of $\mathrm{BC}$ & \\
\hline
\end{tabular}




\begin{tabular}{|llll|}
\hline Respondent characteristics $(\mathbf{n}=\mathbf{2 0 0})$ & & \multicolumn{2}{l|}{ Experiences and expectations regarding BC } \\
\hline Satisfied & $60.5 \%$ & Lack of personal support for patient & $26.1 \%$ \\
\hline Neither satisfied nor dissatisfied & $20 \%$ & Deterioration of therapeutic alliance & $17.4 \%$ \\
Dissatisfied & $10 \%$ & Misinterpretation and treatment errors & $23.1 \%$ \\
Very dissatisfied & $1.5 \%$ & Overburdening patient compliance & $9.3 \%$ \\
& & Privacy risks & $7.7 \%$ \\
& & Low level of customization & $6.7 \%$ \\
& & Lack of therapeutic effectiveness & $5.6 \%$ \\
\hline
\end{tabular}

\section{Experiences with and expectations for BC}

Most respondents who had used BC before (26.5\%) evaluated their experiences as positive (Table 2). Psychotherapists seemed willing to use $B C$ in the future, mainly by integrating $B C$ into regular therapy. The main reported reasons for not opting for BC in the future were the "too impersonal" character of treatment $(55.6 \%)$, doubts regarding their effectiveness $(11.1 \%)$, lack of compatibility with the performed therapy form (11.1\%), and a lack of interest or need (5.6\%). Time savings and patient empowerment were mentioned most often as potential advantages of $\mathrm{BC}$, whereas lack of personal support and deterioration in the therapeutic alliance were seen as main risks. However, most respondents rated the likely impact of $\mathrm{BC}$ on the therapeutic alliance as positive (47.5\%) or neutral (45.5\%). The BC features most likely to be used in the future (Fig. 1) were psychoeducation, online exercises, online diaries, and secure video communication, while chatbots for communication were least likely to be used.

\section{Discrete choice experiment results}

The small drop-out rate during the DCE (3 out of 203) and the type of qualitative comments collected on the overall survey indicated that the respondents were able to understand the choice tasks. Tests for the internal validity of the experimental data showed that straight lining occurred in four instances $(2 \%$ of the sample), and noncompensatory behavior, with a lexicographic score of over $90 \%$, was observed in $16 \%$ of the sample. These values lie close to the respective medians that were reported for these tests in a study summarizing 55 choice experiments [31]. In addition, 30 of these 32 observations exhibit dominant choice behavior for the ratio of online and personal sessions attribute. It is conceivable that for some psychotherapists, this attribute is indeed dominant and that noncompensatory behavior thus does not (always) imply decision heuristics.

The estimated utility function included an ASC and block-specific dummy variables to account for potential bias due to the positioning of the alternatives and the allocated survey version. Linear cnnnifinatinne of thn affantivannace and fanntafann we nqline attributes were selected since the Loading [MathJax]/jax/output/CommonHTML/fonts/TeX/fontdata.js 
assumption of linear preferences regarding these two variables could not be rejected in models estimated only with categorical variables $\left(\chi^{2}=0.02, p=0.89\right.$ and $\chi^{2}=1.46, p=0.23$, respectively). We tested the inclusion of two-way interactions between the additional reimbursement attribute and both the face-toface vs. online attribute and the effectiveness attribute. Both were nonsignificant and therefore excluded in the final model. Testing the inclusion of an interaction between the effectiveness and face-to-face vs. online attributes did yield a significant coefficient, but the signs and sizes of both attribute coefficients became negative and nonsignificant. Therefore, for ease of interpretation, we refrained from including the interaction in the final model.

Table 3 contains the results of the mixed logit model. All main effects coefficients were significantly different from zero (columns 2 and 3 ), indicating their importance in the choice context. The signs of the attribute levels pointed in the expected direction, and the order of the recommendation attribute levels was logical (i.e., higher preference for recommendation by society than by colleagues), providing some confidence in the theoretical validity of the results. The recommendation by professional societies to use a certain $\mathrm{BC}$ intervention was the most important attribute level, while additional reimbursement played a minor role. Greater effectiveness and a higher face-to-face ratio of the BC intervention increased the likelihood of selecting this intervention. Preference heterogeneity was found for all included attributes, as indicated by the significant standard deviations of the parameters (columns 4 and 5). The marginal effects in column 6 demonstrate the change in likelihood of choosing a certain BC intervention if the attribute level changes compared to the reference category (or a unit change for linear variables), conditioning on all other attributes remaining constant. This also allows for a straightforward interpretation of the relative magnitude of the coefficients. Compared to no recommendation, a recommendation by a professional society increases the conditional likelihood of selecting a BC intervention by $25.7 \%$. Using the effectiveness levels from the DCE, a change in effectiveness from 7 out of 10 to 9 out of 10 increased the choice likelihood by a slightly lower factor $(21.0 \%)$. The smallest marginal effect was found for the reimbursement attribute (9.5\%). 
Table 3

DCE results based on a mixed logit model

Preference estimates

Marginal effect

\begin{tabular}{|c|c|c|c|c|c|}
\hline Attributes and levels & Coefficient & $95 \% \mathrm{Cl}$ & SD & $95 \% \mathrm{Cl}$ of $\mathrm{SL}$ & \\
\hline \multicolumn{6}{|l|}{ Recommendation } \\
\hline None & Reference & & & & Reference \\
\hline Colleagues & 1.30 & {$[0.94,1.65]$} & 1.46 & {$[0.97,1.96]$} & $12.2 \%$ \\
\hline Professional societies & 2.70 & {$[2.12,3.27]$} & 2.45 & {$[1.78,3.11]$} & $25.7 \%$ \\
\hline Effectiveness (linear) & 1.08 & {$[0.85,1.30]$} & 1.02 & {$[0.73,1.30]$} & \\
\hline 8 of 10 vs. 7 of 10 & & & & & $10.7 \%$ \\
\hline 9 of 10 vs. 7 of 10 & & & & & $21.0 \%$ \\
\hline Face to face vs. online & 0.03 & {$[0.01,0.04]$} & 0.09 & {$[0.07,0.11]$} & \\
\hline $50: 50$ vs. $20: 80$ & & & & & $7.4 \%$ \\
\hline $80: 20$ vs. $20: 80$ & & & & & $14.2 \%$ \\
\hline \multicolumn{6}{|l|}{ Reimbursement } \\
\hline Proportional to time & Reference & & & & Reference \\
\hline Time + lump sum & 0.95 & {$[0.66,1.23]$} & 1.33 & {$[1.02,1.63]$} & $9.5 \%$ \\
\hline ASC & -0.32 & {$[-1.33,0.69]$} & 1.37 & {$[0.59,2.15]$} & \\
\hline ASC $x$ block2 & 0.05 & {$[-0.97,1.08]$} & 1.39 & {$[0.51,2.27]$} & \\
\hline ASC $x$ block3 & 0.29 & {$[-0.70,1.29]$} & 1.63 & {$[0.58,2.67]$} & \\
\hline Log likelihood & $-1,568$ & & & & \\
\hline AIC & 3,223 & & & & \\
\hline $\mathrm{BIC}$ & 3,521 & & & & \\
\hline Respondents & 200 & & & & \\
\hline Observations & 6,400 & & & & \\
\hline
\end{tabular}

Note. Attributes were dummy coded. Coefficients refer to the mean preference estimates and standard deviations (SD) of the distribution around the means. Uncertainty around the mean and SDs is shown using $95 \%$ confidence intervals (Cls).

In terms of the subgroups, we found significantly different coefficient estimates for psychotherapists Loading [MathJax]/jax/output/CommonHTML/fonts/TeX/fontdata.js $\mathrm{p}<0.01$ ), for respondents being younger or older 
than 50 years $\left(x^{2}=17.07, p<0.01\right)$, and for therapists predominantly practicing behavioral therapy vs. psychodynamic psychotherapy $\left(x^{2}=16.62, p<0.01\right)$. Figure 2 presents the coefficient estimates for the respective subgroups. Younger therapists put more weight on recommendations to use a BC format, the potential effectiveness of the intervention and additional reimbursement, while a higher share of face-toface vs. online time was less important to them. Inpatient therapists are more influenced by recommendations than are outpatient therapists, who preferred a higher share of face-to-face vs. online time. Face-to-face time was significantly less important for therapists predominantly conducting behavioral therapy than for therapists conducting psychodynamic psychotherapy.

\section{Note}

Interaction term significant at the $10 \%$ level. Abbreviation: f2f-online, ratio of face-to-face vs. online time.

\section{Discussion}

Conducting a survey, including a DCE, with a sample of 200 psychotherapists from Germany, our study assessed psychotherapists' experiences, expectations and preferences regarding BC psychotherapy formats, which combine the application of eMHls and regular psychotherapy. The study's main contributions are as follows. First, to our knowledge, this is the first DCE exploring preferences among psychotherapists for eMHIs or BC. Second, our survey described and distinguished among concrete BC features and application scenarios, making our analysis as tangible as possible for psychotherapists. Third, this study is the first survey, and DCE, that has investigated preferences for BC in the context of Germany, an example of a country with low e-mental health utilization.

In general, we found rather positive attitudes towards BC among German psychotherapists and a strong willingness to use $B C$ in the future. This finding was surprising, as previous studies on the attitudes of German-speaking psychotherapists towards eMHIs and BC indicated that they had reservations [14, 17], but is in concordance with the more optimistic attitudes of Dutch therapists [12-13, 16]. Most therapists prefer using BC features such as psychoeducation, online exercises, online diaries, and secure video communication integrated into regular therapeutic cycles instead of pre- or post-therapy applications. Similar results were found in a Delphi study in which Dutch therapists found practical therapy components such as assignments, diaries and psychoeducation most suitable for a digital format [12]. This preference was also found in other studies among therapists from the Netherlands and Austria [1516]. Most respondents perceived a positive or neutral impact of $B C$ on the therapeutic relationship. It is not surprising that therapists conducting psychodynamic therapy are less likely to use BC treatments with a large online component than behavioral therapists, as $\mathrm{BC}$ is mainly grounded in $\mathrm{CBT}$, which was also found in other studies $[13,14-15,17]$. The main reasons for not applying $B C$ were lack of personal contact, doubts regarding effectiveness and lack of personal interest. These findings are in concordance with previous research across different countries, where fears of losing contact with patients, not offering patients the amount of help they need, or making treatment mistakes were frequently expressed [12-13, 
accompanying in-person contact is perceived as a central need when using eMHIs [10]. The main stated advantages of $\mathrm{BC}$ among therapists coincide with the first findings referring to patient empowerment, patient training in self-management skills, and the perception of increased treatment effectiveness, which was also shown in other studies [35]. The preference results showed that a recommendation to use a BC treatment format made by a professional society (psychotherapist association) was most influential when choosing between the treatment scenarios in the choice experiment. The effect was even larger among therapists working in an inpatient setting. While greater effectiveness and a larger share of faceto-face vs. online time were important as well, additional reimbursement for BC was less decisive, especially among older providers. The financial dimension apparently did not play a significant role among German therapists, which is surprising because in previous research, the primary incentive for using eMHIs among mental health stakeholders was the expected cost-effectiveness [11, 36].

\section{Limitations}

Although our study was carefully designed and tests for internal validity revealed satisfactory results, we need to acknowledge the following research limitations related to the external validity of our findings. In Germany, both qualified psychologists and physicians (including psychiatrists), who have completed several years of specialist practical training and certification in psychotherapy, are authorized to practice psychotherapy. While providing us direct access to a sufficiently large pool of psychotherapists, the selected sampling agency (DocCheck) has a drawback in that most of the panel's members have a medical background, resulting in our sample mainly consisting of physicians with psychotherapeutic training (89\%). The share of medical psychotherapists among office-based Statutory Health Insurance psychotherapists was $24 \%$ in 2017 . However, this represents only one portion of all ambulatory psychotherapy providers. This share is likely to be higher in outpatient departments of psychiatric and psychosomatic facilities, which also provide ambulatory psychotherapy and are likely users of eMHIs. However, data about the educational background of all therapists providing ambulatory psychotherapy in Germany are not available. Thus, we estimate that the share of medical psychotherapists among all therapists providing ambulatory psychotherapy in Germany is lower in the total population than in our sample.

A further limitation relates to the selected characteristics in the choice experiment. While these were carefully selected using standard practices, including interviews with providers, the experimental design could have omitted important characteristics, in part because no choice experiments have been conducted in this novel but emerging research area. That BC treatment formats are also new to many psychotherapists, who often have little to no prior experience, may also be seen as a limitation. While the DCE allows us to present hypothetical scenarios, the structure, mechanism, and potential benefits/risks of $\mathrm{BC}$ thus remained quite abstract to respondents.

\section{Conclusion}


German medical psychotherapists, despite having little previous experience with BC, showed positive attitudes towards $B C$ together with a strong intention for future use in treatments. Similar to therapists from other countries, they appreciate the use of eMHIs for practical CBT-oriented therapy tasks while stressing the importance of maintenance of the therapeutic relationship through the larger number of parallel face-to-face sessions. Our findings from the DCE suggest a strong preference for BC treatment that includes an online component approved by a professional psychotherapist society. This highlights the importance of including professional associations early in the development, application, and evaluation of $B C$ treatments to encourage uptake. Our results suggest that German psychotherapists care less about the additional reimbursement but are ready to use $B C$ formats if they are convinced of the effectiveness and trustworthiness of the online components. Thus, financial incentives may not be very useful for encouraging wider use of $\mathrm{BC}$ in Germany, and assessment along with recommendations from trusted institutions for online components of $\mathrm{BC}$ would be recommended.

\section{Abbreviations}

$\mathrm{AIC}-$

ASC - Alternative specific constant

BC - Blended Care

$\mathrm{BIC}-$

CBT - Cognitive Behavior Therapy

$\mathrm{Cl}$ - Confidence Interval

COVID-19 - Coronavirus Disease 2019

DCE - Discrete Choice Experiment

eMHIs - Online- or Web-based Therapeutic Interventions

JMP software - Statistical Software

ISPOR - International Society for Pharmacoeconomics and Outcomes Research

SD - Standard Deviations

UTAUT - Unified Theory of Acceptance and Use of Technology

\section{Declarations}

\section{Funding}


Sebastian F. Himmler has received funding from the European Union's Horizon 2020 research and innovation programme under the Marie Skłodowska-Curie grant agreement No 721402.

\section{Availability of data and materials}

The data-sets generated and/or analysed during the current study are available in the following repository "Preferences for e-Mental Health Interventions in Germany: A Discrete Choice Experiment", available at https://osf.io/af2rw/?view_only=e148be5df318487486bd2a406369abf1

\section{Authors' contributions}

Study conception and design: EP, SH, JS. Data collection, statistical expertise, analysis and interpretation of data: EP, SH. Manuscript preparation, supervision, administrative support and critical revision of the paper. EP, SH, JS. All authors read and approved the final manuscript.

\section{Ethics approval}

The study did not require ethical approval as the form of the study was opinion seeking for the purpose of market research, with the subject matter limited to topics that are strictly within the professional competence of the participants. Please check the national guidelines for ethics in research for Germany here: https://www.dfg.de/foerderung/faq/geistes_sozialwissenschaften/ (the summary in English is available here: https://datawizkb.leibniz psychology.org/index.php/before-my-project-starts/what-shouldi-know-about-ethics/)

In addition, no vulnerable groups were included, the data were completely anonymous, there was no risk of disclosure, and the data collected were not sensitive in nature.

\section{Consent to participate}

Before data were collected, all participants were informed of the purpose of the study and informed written consent was obtained. In addition, all participants were assured that their anonymity and confidentiality would be maintained and that they were entitled to drop out of the study at any time.

\section{Conflicts of Interest}

The authors declare that they have no competing interests.

\section{References}

1. Wind, T. R., Rijkeboer, M., Andersson, G., \& Riper, H. (2020). The COVID-19 pandemic: The 'black swan' for mental health care and a turning point for e-health. Internet Interv, 20, 100317. doi:10.1016/j.invent.2020.100317 
2. Christensen, H., \& Hickie, I. B. (2010). Using e-health applications to deliver new mental health services. Medical Journal of Australia, 192(S11). doi:10.5694/j.1326-5377.2010.tb03695.x

3. Barak, A., Klein, B., \& Proudfoot, J. G. (2009). Defining internet-supported therapeutic interventions. Ann Behav Med, 38(1), 4-17. doi:10.1007/s12160-009-9130-7

4. Barak, A., Hen, L., Boniel-Nissim, M., \& Shapira, N. a. (2008). A Comprehensive Review and a MetaAnalysis of the Effectiveness of Internet-Based Psychotherapeutic Interventions. Journal of Technology in Human Services, 26(2-4), 109-160. doi:10.1080/15228830802094429

5. Grist, R., \& Cavanagh, K. (2013). Computerised Cognitive Behavioural Therapy for Common Mental Health Disorders, What Works, for Whom Under What Circumstances? A Systematic Review and Metaanalysis. Journal of Contemporary Psychotherapy, 43(4), 243-251. doi:10.1007/s10879-013-9243-y

6. Musiat, P., Goldstone, P., \& Tarrier, N. (2014). Understanding the acceptability of e-mental health-attitudes and expectations towards computerised self-help treatments for mental health problems. $B M C$ Psychiatry, 14, 109. doi:10.1186/1471-244X-14-109

7. Renn, B. N., Hoeft, T. J., Lee, H. S., Bauer, A. M., \& Arean, P. A. (2019). Preference for in-person psychotherapy versus digital psychotherapy options for depression: survey of adults in the U.S. NPJ Digit Med, 2, 6. doi:10.1038/s41746-019-0077-1

8. Wentzel, J., van der Vaart, R., Bohlmeijer, E. T., \& van Gemert-Pijnen, J. E. (2016). Mixing Online and Face-to-Face Therapy: How to Benefit From Blended Care in Mental Health Care. JMIR Ment Health, 3(1), e9. doi:10.2196/mental.4534

9. Etzelmueller, A., Radkovsky, A., Hannig, W., Berking, M., \& Ebert, D. D. (2018). Patient's experience with blended video- and internet based cognitive behavioural therapy service in routine care. Internet Interv, 12, 165-175. doi:10.1016/j.invent.2018.01.003

10. Phillips E, H. S., Schreyögg J (forthcoming). (2021). Preferences for e-mental health interventions in Germany: a discrete choice experiment. Value in Health.

11. Topooco, N., Riper, H., Araya, R., Berking, M., Brunn, M., Chevreul, K., . . Andersson, G. (2017). Attitudes towards digital treatment for depression: A European stakeholder survey. Internet Interv, 8, 1-9. doi:10.1016/j.invent.2017.01.001

12. van der Vaart, R., Witting, M., Riper, H., Kooistra, L., Bohlmeijer, E. T., \& van Gemert-Pijnen, L. J. (2014). Blending online therapy into regular face-to-face therapy for depression: content, ratio and preconditions according to patients and therapists using a Delphi study. BMC Psychiatry, 14. doi:10.1186/s12888-014-0355-z

13. Mol, M., van Genugten, C., Dozeman, E., van Schaik, D. J. F., Draisma, S., Riper, H., \& Smit, J. H. (2020). Loading [MathJax]/jax/output/CommonHTML/fonts/TeX/fontdata.js epression Is Challenging: A Qualitative Study on 
Therapists' Perspectives. J Clin Med, 9(1). doi:10.3390/jcm9010091

14. Schuster, R., Leitner, I., Carlbring, P., \& Laireiter, A. R. (2017). Exploring blended group interventions for depression: Randomised controlled feasibility study of a blended computer- and multimedia-supported psychoeducational group intervention for adults with depressive symptoms. Internet Interv, 8, 63-71. doi:10.1016/j.invent.2017.04.001

15. Schuster, R., Pokorny, R., Berger, T., Topooco, N., \& Laireiter, A. R. (2018). The Advantages and Disadvantages of Online and Blended Therapy: Survey Study Amongst Licensed Psychotherapists in Austria. J Med Internet Res, 20(12), e11007. doi:10.2196/11007

16. Dijksman, I., Dinant, G. J., \& Spigt, M. (2017). The Perception and Needs of Psychologists Toward Blended Care. Telemed J E Health, 23(12), 983-995. doi:10.1089/tmj.2017.0031

17. Schröder, J., Berger, T., Meyer, B., Lutz, W., Hautzinger, M., Späth, C., . . Moritz, S. (2017). Attitudes Towards Internet Interventions Among Psychotherapists and Individuals with Mild to Moderate Depression Symptoms. Cognitive Therapy and Research, 41(5), 745-756. doi:10.1007/s10608-017-9850-0

18. Erbe, D., Eichert, H. C., Riper, H., \& Ebert, D. D. (2017). Blending Face-to-Face and Internet-Based Interventions for the Treatment of Mental Disorders in Adults: Systematic Review. J Med Internet Res, 19(9), e306. doi:10.2196/jmir.6588

19. Bridges, J. F., Hauber, A. B., Marshall, D., Lloyd, A., Prosser, L. A., Regier, D. A., . . Mauskopf, J. (2011). Conjoint analysis applications in health-a checklist: a report of the ISPOR Good Research Practices for Conjoint Analysis Task Force. Value Health, 14(4), 403-413. doi:10.1016/j.jval.2010.11.013

20. Venkatesh, V., Morris, M. G., Davis, G. B., \& Davis, F. D. (2003). User acceptance of information technology: Toward a unified view. Mis Quarterly, 27(3), 425-478. doi: 10.2307/30036540

21. Dulle, F. W., \& Minishi-Majanja, M. K. (2011). The suitability of the Unified Theory of Acceptance and Use of Technology (UTAUT) model in open access adoption studies. Information Development, 27(1), 3245. doi:10.1177/0266666910385375

22. Hennington, A., \& Janz, B. D. (2007). Information Systems and Healthcare XVI: Physician Adoption of Electronic Medical Records: Applying the UTAUT Model in a Healthcare Context. Communications of the Association for Information Systems, 19. doi:10.17705/1cais.01905

23. Reed Johnson, F., Lancsar, E., Marshall, D., Kilambi, V., Muhlbacher, A., Regier, D. A., . . Bridges, J. F. (2013). Constructing experimental designs for discrete-choice experiments: report of the ISPOR Conjoint Analysis Experimental Design Good Research Practices Task Force. Value Health, 16(1), 3-13. doi:10.1016/j.jval.2012.08.2223

24. Campbell, D., \& Erdem, S. (2019). Including Opt-Out Options in Discrete Choice Experiments: Issues to Loading [MathJax]/jax/output/CommonHTML/fonts/TeX/fontdata.js 324-6

Page $17 / 20$ 
25. Rolstad, S., Adler, J., \& Ryden, A. (2011). Response burden and questionnaire length: is shorter better? A review and meta-analysis. Value Health, 14(8), 1101-1108. doi:10.1016/j.jval.2011.06.003

26. Orme, B. (1998). Sample Size Issues for Conjoint Analysis Studies, Sawtooth Software Research Paper Series. Washington: Sawtooth Software Inc., Sequim

27. McFadden, D. (1974). Economic theory and mathematical economics. In P. Zarembka (Ed.), Frontiers in econometrics (pp. 105-142). New York: Academic Press.

28. Lancsar, E., Fiebig, D. G., \& Hole, A. R. (2017). Discrete Choice Experiments: A Guide to Model Specification, Estimation and Software. Pharmacoeconomics, 35(7), 697-716. doi:10.1007/s40273-0170506-4

29. Soekhai, V., de Bekker-Grob, E. W., Ellis, A. R., \& Vass, C. M. (2019). Discrete Choice Experiments in Health Economics: Past, Present and Future. Pharmacoeconomics, 37(2), 201-226. doi:10.1007/s40273018-0734-2

30. Hensher, D. A. R., John M.; Greene, William H. (2015). Applied Choice Analysis. Cambridge Cambridge University Press.

31. Johnson, F. R., Yang, J. C., \& Reed, S. D. (2019). The Internal Validity of Discrete Choice Experiment Data: A Testing Tool for Quantitative Assessments. Value Health, 22(2), 157-160. doi:10.1016/j.jval.2018.07.876

32. Krucien, N., Watson, V., \& Ryan, M. (2017). Is Best-Worst Scaling Suitable for Health State Valuation? A Comparison with Discrete Choice Experiments. Health Econ, 26(12), e1-e16. doi:10.1002/hec.3459

33. Bundesärztekammer. (2020). Ärztestatistik 2019. Retrieved from https://www.bundesaerztekammer.de/ueber-uns/aerztestatistik/aerztestatistik-2019/

34. Melcop, N., von Werder, T., Sarubin, N., \& Benecke, A. (2019). The Role of Psychotherapy in the German Health Care System: Training Requirements for Psychological Psychotherapists and Child and Adolescent Psychotherapists, Legal Aspects, and Health Care Implementation. Clinical Psychology in Europe, 1(4). doi:10.32872/cpe.v1i4.34304

35. Mathiasen, K., Andersen, T. E., Riper, H., Kleiboer, A. A., \& Roessler, K. K. (2016). Blended CBT versus face-to-face CBT: a randomised non-inferiority trial. BMC Psychiatry, 16(1), 432. doi:10.1186/s12888-016$1140-y$

36. Andersson, G., Cuijpers, P., Carlbring, P., Riper, H., \& Hedman, E. (2014). Guided Internet-based vs. faceto-face cognitive behavior therapy for psychiatric and somatic disorders: a systematic review and metaanalysis. World Psychiatry, 13(3), 288-295. doi:10.1002/wps.20151 
Figures

\section{Likely to use...}

Online psychoeducational modules

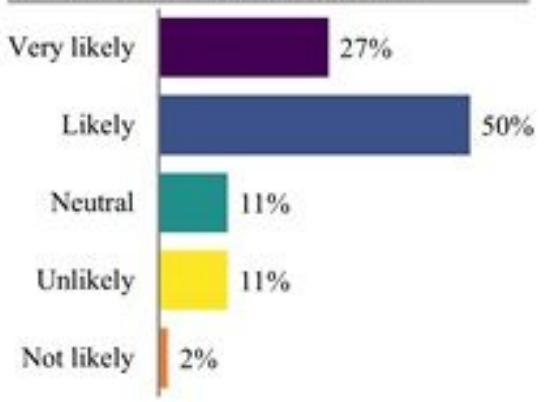

Secure video communication

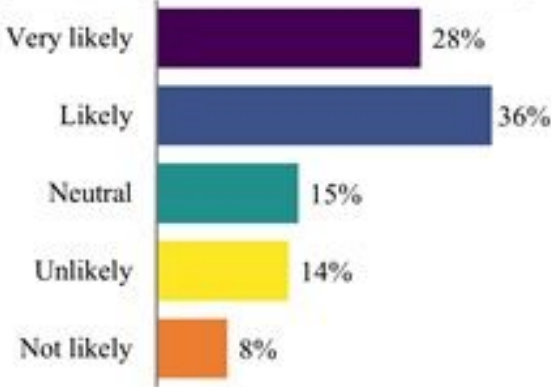

Online exercises based on CBT

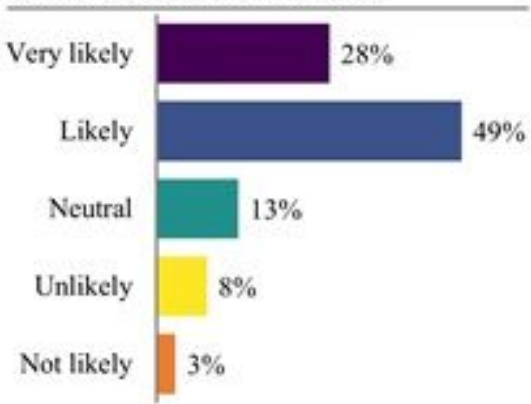

Computer games supporting therapy

Very likely

Likely

Neutral

Unlikely

Not likely

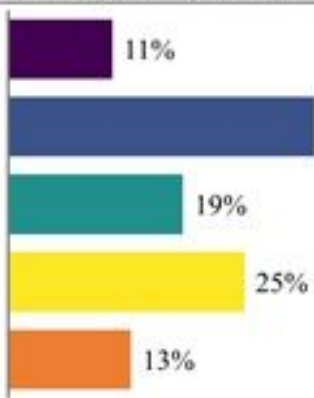

Online diaries

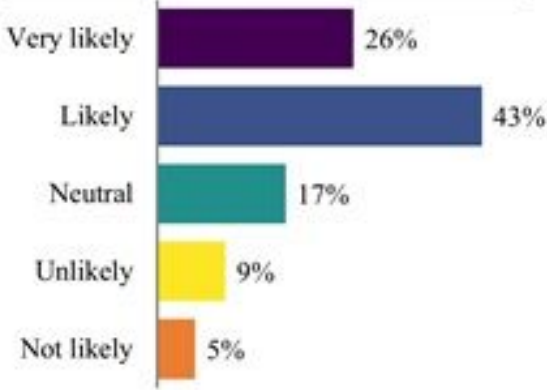

Chatbots for communication purposes

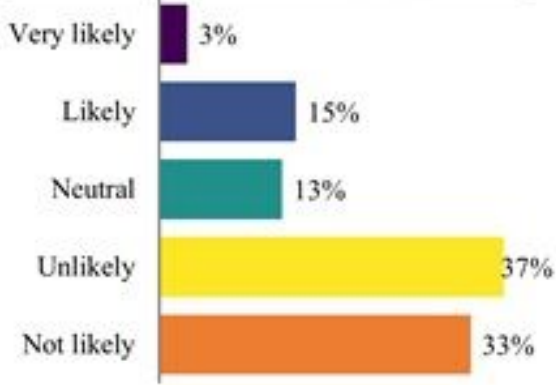

\section{Figure 1}

Likelihood of using BC features 

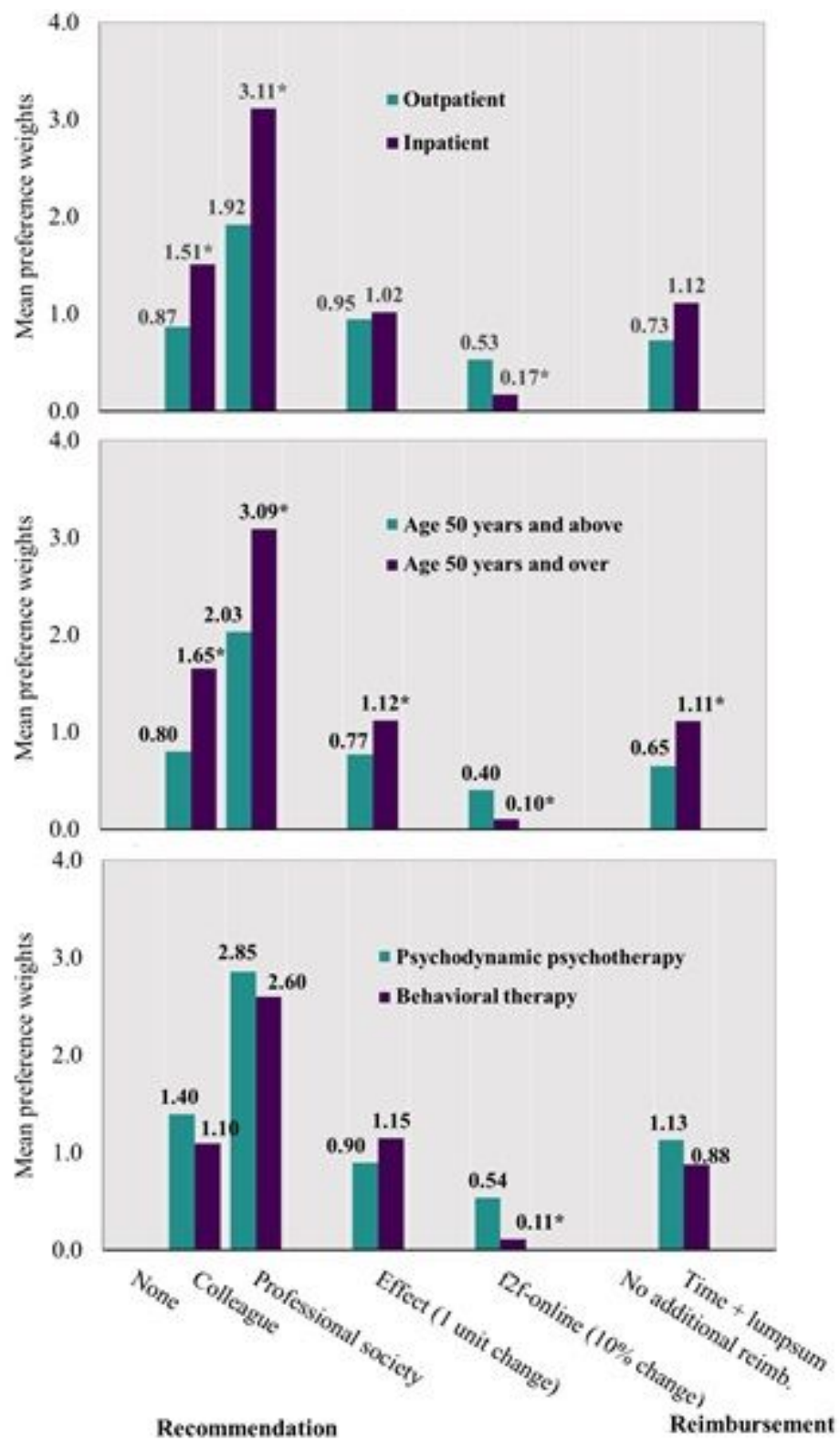

\section{Figure 2}

Subgroup results for age, outpatient vs. inpatient setting, and type of therapy 